\title{
Improving medication adherence in hypercholesterolemia: challenges and solutions
}

This article was published in the following Dove Press journal:

Vascular Health and Risk Management

6 November 2014

Number of times this article has been viewed

\section{Justin Gatwood'}

James E Bailey²

'University of Tennessee Health Science Center, College of Pharmacy, ${ }^{2}$ University of Tennessee Health Science Center, Center for Health System Improvement, Memphis, TN, USA

Video abstract

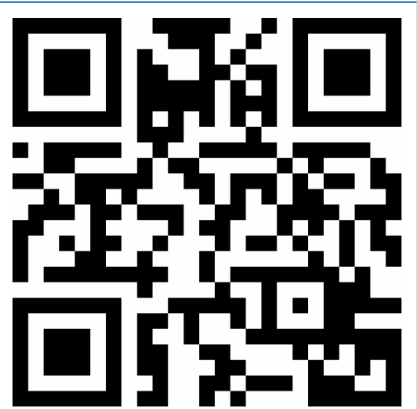

Point your SmartPhone at the code above. If you have a QR code reader the video abstract will appear. Or use: http://dvpr.es//ri4ej0
Correspondence: Justin Gatwood University of Tennessee College of Pharmacy, 88I Madison Ave, Memphis, TN 38163, USA

$\mathrm{Tel}+\mathrm{I} 9014487215$

Email jgatwood@uthsc.edu
Abstract: Medication nonadherence is a prevalent public health issue that contributes to significant medical costs and detrimental health outcomes. This is especially true in patients with hypercholesterolemia, a condition affecting millions of American adults and one that is associated with increased risk for coronary and cerebrovascular events. Considering the magnitude of outcomes related to this disease, the medical community has placed significant emphasis on addressing the treatment for high cholesterol, and progress has been made in recent years. However, poor adherence to therapy continues to plague health outcomes and more must be understood and done to address suboptimal medication taking. Here we provide an overview of the reasons for poor medication adherence in patients with hypercholesterolemia and describe recent efforts to curb nonadherence. Suggested approaches for improving medication taking in patients with high cholesterol are also provided to guide practitioners, patients, and payers.

Keywords: medication use, lipid management, cardiovascular disease

\section{Introduction}

As of 2010, nearly $15 \%$ of American adults had high total cholesterol, placing them at increased risk of detrimental health outcomes. ${ }^{1}$ Moreover, substantial costs are associated with high cholesterol levels, contributing to the more than US \$400 billion in direct and indirect costs associated with cardiovascular disease. ${ }^{2}$ While recent trends in uncontrolled low-density lipoprotein (LDL) may suggest that progress has been made, significant opportunity for improvement remains in the controlling of cholesterol levels. ${ }^{3}$

While a myriad of medication options exist to treat hypercholesterolemia, and given that generic cholesterol medication availability has grown in recent years, significant barriers still limit the effectiveness of existing treatments. Specifically, medication nonadherence - the extent to which patients take medications as prescribed - remains prevalent and acts as a major barrier to improving health outcomes in patients with high cholesterol. ${ }^{4}$ Current estimates suggest that nonadherence to medications indicated for hypercholesterolemia results in US \$44 billion in avoidable health care costs and contributes to increased hospitalizations. ${ }^{5,6}$ While multiple investigations have aimed to curb the issue of nonadherence, more must be done to improve the medication-taking habits of patients with high cholesterol in order to decrease the risk of detrimental outcomes and reduce unnecessary health care costs.

This review highlights the current state of hypercholesterolemia treatment in the United States with a specific focus on the impact that medication nonadherence has on outcomes in patients with this condition. Furthermore, this paper examines the 
strategies that have been applied to date aimed at improving the use of cholesterol-lowering medications, as well as the challenges that have impeded progress. Strategies to improve adherence, from the perspective of multiple stakeholders, are also suggested to guide future interventions and patient encounters.

\section{Scope of the problem Epidemiology}

Recent estimates highlight the extent of elevated cholesterol levels in the US. As of 2008, mean total serum cholesterol levels in the US for men and women were $195 \mathrm{mg} / \mathrm{dL}$ and $201 \mathrm{mg} / \mathrm{dL}$, respectively. ${ }^{7}$ High levels of total cholesterol are noticeably higher in particular subgroups of the population, specifically non-Hispanic females and Mexican-American males; the prevalence of total cholesterol in excess of $240 \mathrm{mg} / \mathrm{dL}$ exceeds $15 \%$ in both groups. ${ }^{8}$ Additionally, approximately one in three American adults has high circulating levels of LDL cholesterol, only one-third of which has this condition under control. ${ }^{9}$ Recent data from the nationwide Reasons for Geographic and Racial Differences in Stroke study ${ }^{10}$ indicated that statins were only used by $58.4 \%$ of those with coronary heart disease (CHD), $41.7 \%$ of those with a history of stroke or abdominal aortic aneurysm, $40.4 \%$ of those with diabetes, and $20.7 \%$ of those with 10-year Framingham Risk Scores of over 20\%. Statin underuse and poor cholesterol control contributes to an estimated 635,000 new coronary events, nearly 800,000 new or recurrent strokes, and approximately one in every six deaths each year. ${ }^{7}$ Even after recent improvements in outcomes, heart disease remains the number one killer of Americans for both men and women. ${ }^{11}$

\section{Resource utilization}

Significant health care resources are expended and costs are attributed to managing hypercholesterolemia and its related conditions each year. In 2009, over 12 million physician office visits were primarily focused on CHD, specifically coronary atherosclerosis, and nearly 100 million visits - about one in every ten - included a cholesterol test, exceeding both the number of visits requesting glucose or hemoglobin A1C testing. ${ }^{12}$ In 2010 , over 1.3 million inpatient stays were primarily due to CHD, with over 3 million estimated procedures (percutaneous coronary intervention, bypass, catheterizations, and placement of defibrillators and pacemakers) being completed throughout the year. ${ }^{8}$ In order to address disease related to high cholesterol levels, nearly $25 \%$ of adults in America now take some form of cholesterol-lowering medication; ${ }^{13}$ however, a significant number of adults with hypercholesterolemia still go untreated. ${ }^{9}$ Current projections suggest that direct medical and indirect costs due to CHD will approach US $\$ 130$ billion by the end of 2015, and this figure is expected to exceed US $\$ 150$ billion by the end of this decade. ${ }^{14}$ Significant efforts must be made to address the substantial impact that hypercholesterolemia has on Americans and the US health care system.

\section{Current treatment}

Treatment recommendations for hypercholesterolemia have recently undergone a sea change. The new American College of Cardiology/American Heart Association (ACC/AHA) guidelines are somewhat controversial, and many providers are reasonably confused about which guidelines to follow and who to treat. ${ }^{15-17}$ As shown in Table 1, the most widely accepted Advanced Treatment Panel III (ATP-III) cholesterol treatment guidelines of the National Cholesterol Education Program recommend that approximately one-third of US adults (43.2 million) undertake medication therapy for high cholesterol, whereas the most recent ACC/AHA guidelines recommend that over half of American adults (56.0 million) undertake treatment. ${ }^{18}$ Extrapolation from the National Health and Nutrition Examination Survey population suggests that the new guidelines for hypercholesterolemia would recommend medication therapy to $87.5 \%$ of men aged $60-75$ years and $53.6 \%$ of women in this age range. ${ }^{18}$ Similar extrapolation from the Rotterdam Study cohort of adults aged 55 years and older suggests that $96.4 \%$ of men and $65.8 \%$ of women would require treatment under the ACC/AHA guidelines compared with $66.1 \%$ of men and $35.5 \%$ of women for the ATP-III and $66.1 \%$ of men and $39.1 \%$ of women for the European Society of Cardiology (ESC) guidelines. ${ }^{17,19,20}$ Although experts generally support the largely concordant aggressive ACC/AHA, ATP-III, and ESC treatment recommendations for secondary prevention in patients with $\mathrm{CHD}$ or arteriosclerotic cardiovascular disease (ASCVD), and for primary prevention in the highest-risk groups, many express doubts regarding the appropriateness of recommendations for lower-risk groups. ${ }^{15-17,21}$

Debates regarding the ACC/AHA guidelines largely center on their methods for risk estimation. Critics note that the ASCVD pooled cohort risk equations, while generally showing fair discrimination, systematically overestimate risk, thereby overstating the need for treatment. ${ }^{15-17,21,22}$ For the highest-risk group with clinical CHD/ASCVD, as few as five to ten patients would need to be treated for 10 years to prevent one heart attack in that period (number needed 
Table I Recommended treatment strategies for hypercholesterolemia

\begin{tabular}{|c|c|c|}
\hline & $\begin{array}{l}200 \text { I Advanced Treatment Panel III/National } \\
\text { Cholesterol Education Program guidelines }{ }^{77,78}\end{array}$ & $\begin{array}{l}2013 \text { American College of Cardiology/American } \\
\text { Heart Association guidelines } s^{79,80}\end{array}$ \\
\hline Populations treated & $\begin{array}{l}\text { I. Adults with } C H D \text { or } C H D \text { risk equivalents } \\
\text { and } L D L-C>100 \mathrm{mg} / \mathrm{dL} \\
\text { 2. Adults with } 2+C H D \text { risk factors } \\
\text { (I0-year risk } 10 \%-20 \% \text { ) and LDL-C }>130 \mathrm{mg} / \mathrm{dL} \\
\text { 3. Adults with } 2+C H D \text { risk factors } \\
\text { (10-year risk }<10 \% \text { and } L D L-C>160 \mathrm{mg} / \mathrm{dL} \\
\text { 4. Adults with } 0-1 \mathrm{CHD} \text { risk factors } \\
\text { and LDL-C }>190 \mathrm{mg} / \mathrm{dL}\end{array}$ & $\begin{array}{l}\text { 1. Adults with clinical atherosclerotic cardiovascular disease } \\
\text { 2. Adults with primary elevations of LDL-C }>190 \mathrm{mg} / \mathrm{dL} \\
\text { 3. Adults with diabetes, aged } 40-75 \text { years, with LDL-C } \\
70-189 \mathrm{mg} / \mathrm{dL} \text { and without clinical ASCVD } \\
\text { 4. Adults without clinical ASCVD or diabetes with } \\
\text { LDL-C } 70-189 \mathrm{mg} / \mathrm{dL} \text { and estimated } 10 \text {-year } \\
\text { ASCVD risk }>7.5 \%\end{array}$ \\
\hline Risk assessment method & $\begin{array}{l}\text { LDL-C and CHD risk factor assessment } \\
\text { based on Framingham data }\end{array}$ & $\begin{array}{l}\text { CVD risk factor assessment based on pooled CVD data } \\
\text { including total cholesterol }\end{array}$ \\
\hline 10-year risk calculator & Framingham $^{81}$ & Pooled cohort equations ${ }^{82}$ \\
\hline $\begin{array}{l}\text { Recommended } \\
\text { treatments }\end{array}$ & $\begin{array}{l}\text { Lifestyle modification with addition } \\
\text { of cholesterol-lowering medications (primarily } \\
\text { statins) based on LDL cholesterol and risk category }\end{array}$ & $\begin{array}{l}\text { Statin cholesterol-lowering medications for all groups with } \\
\text { statin therapy intensity determined based on risk category } \\
\text { alone plus lifestyle modification }\end{array}$ \\
\hline Treatment monitoring & Yes, treat to recommended LDL levels & Yes, treat independently of observed LDL levels \\
\hline Recommended adult & Total: 43.2 million people (37.5\%) & Total: 56.0 million (48.6\%) \\
\hline United States treatment & Aged $40-59$ years: 20.3 million people $(27.0 \%)$ & Aged $40-59$ years: 22.3 million ( $29.7 \%)$ \\
\hline population $(2010)^{18}$ & Aged $60-75$ years: I 3.5 million people (47.8\%) & Aged $60-75$ years: 21.9 million (77.3\%) \\
\hline
\end{tabular}

Abbreviations: CHD, coronary heart disease; LDL-C, low-density lipoprotein cholesterol; ASCVD, arteriosclerotic cardiovascular disease; CVD, cardiovascular disease; LDL, low-density lipoprotein.

to treat [NNT] range: five to ten), but for relatively low-risk patients for whom medication therapy is recommended under the guidelines, NNT approaches 300-500 to prevent one heart attack in 10 years of therapy. ${ }^{23-25}$ High NNTs for cholesterol medication therapy in low to moderate risk groups raise appropriate concerns regarding the application of these thresholds for treatment indiscriminately in individual patients. However, even using the more conservative ATP-III and ESC recommendations for treatment (Table 1), the need for treatment is immense; by all accounts, high cholesterol represents a major public health problem.

However, the need for long-term treatment with statin medications in order to confer benefit makes concerns regarding cholesterol medication adherence particularly acute. Medication treatment for the primary and secondary prevention of CHD is daily, and it typically must be continued for 10-30 years on a daily basis to confer benefit. In addition, unlike therapy for acute symptomatic conditions, no symptomatic improvements are associated with therapy for high cholesterol. To the contrary, some patients experience adverse effects, including myalgias, rhabdomyolysis, nausea and vomiting, liver toxicity, increased incidence of diabetes, and mental status changes. Furthermore, therapy can be associated with potentially serious drug-drug interactions; however, recent summaries of the evidence suggest that statins are not associated with significant levels of serious adverse effects, and they are widely considered safe..$^{21,26}$
Taken together, these considerations - high prevalence of the condition, treatment burden (requirement of daily medication), large time lag with little or no benefit for most individuals, lack of symptomatic benefit, and adverse medication effects - make medication adherence for hypercholesterolemia a major public health problem. A population-based care approach demands that we find ways to deliver this proven effective preventive care approach to large populations with efficiency.

\section{Adherence}

While multiple pharmaceutical treatment options are available to patients with hypercholesterolemia, the effectiveness of these treatments is limited by the extent to which patients adhere to the medication regimen prescribed by their provider. For patients with chronic conditions, including high cholesterol, this refers to both the daily taking of medication, as well as to the initiation and ongoing prescription filling of longterm therapies. Multiple studies have described the extent of nonadherence in patients with hypercholesterolemia and have provided estimates in a variety of patient populations, as well as insight into contributing factors.

Across studies, estimates for adherence or persistence to cholesterol-lowering medications have been observed to range depending on the underlying conditions, point of therapy, and the method used to assess medication use. When averaged across studies examining lipid-lowering therapies, 
adherence (as defined by the achievement of a medication possession ratio greater than $80 \%$ ) was achieved in approximately $50 \%$ of patients examined, with approximately two-thirds of patients remaining persistent at 1 year. ${ }^{27}$ After 9 months of newly initiated statin therapy, only $56 \%$ of patients remained persistent and declined even further after the first year; average adherence was also suboptimal and was below $60 \%$ across all patients. ${ }^{28}$ Similarly, among commercially insured adults, $43 \%$ never returned to statin therapy following an observed stoppage of at least 90 days. ${ }^{29}$

An interesting pattern of medication use has also been observed in patients following a distinct cardiac event or with well-established disease. Even though the odds of adherence have been shown to be slightly higher after a hospitalization, issues with remaining adherent appear relatively soon after discharge.$^{30-32}$ In a study of patients discharged for acute myocardial infarction, primary nonadherence (the failure to initiate a prescribed therapy) was suboptimal and over $10 \%$ of patients failed to fill their lipid-lowering agent 1 week after discharge; fill rates did not reach $90 \%$ until 30 days postdischarge. ${ }^{33}$ In another multicenter, prospective cohort study, similarly poor fill rates were observed prior to this, where approximately $70 \%$ of postmyocardial infarction patients had filled their statin 1 month after discharge. ${ }^{34}$ Among patients with established coronary artery disease, adherence has been observed to decline sharply in the first 6 months following initial therapy. ${ }^{30}$ At 18 months of planned statin therapy, nearly $30 \%$ of men with CHD within the Veteran Affairs system remained adherent; the odds of poor adherence were particularly high among new users of statins. ${ }^{35}$ Such ranges in estimates add weight to the prominence of the nonadherence problem in patients with hypercholesterolemia.

The result of significant departures from adherence to prescribed treatment regimens is an increase in odds of the patients experiencing detrimental health outcomes. A metaanalysis of adherence studies of patients with hypercholesterolemia found that adherence to therapy was related to a $25 \%$ decrease in the risk for a null or poor outcome compared to those who were nonadherent. ${ }^{36}$ Similarly, following hospitalization for acute myocardial infarction, statin nonadherence has been associated with an up to $25 \%$ increased hazard for mortality ${ }^{37}$ a significant increase in the risk of hospitalization and mortality has also been observed in patients with coronary artery disease due to nonadherence to statins. ${ }^{38}$ Conversely, a protective effect of adherence against recurrent myocardial infarction, cardiovascular hospitalization, or death has been observed in multiple studies, with the odds of some outcomes increasing as adherence worsens..$^{39,40}$
Furthermore, decreased levels of adherence to hypercholesterolemia medications have been associated with a general increases in medical costs; estimates of avoidable costs for this condition due to medication nonadherence exceed those for hypertension and diabetes combined. ${ }^{5}$ However, patients remaining adherent to statin therapy have been associated with lower all-cause health care costs, particularly when compared to those following their therapy less than $60 \%$ of the time. ${ }^{40}$ Considering both the physiological and economic outcomes of poor adherence to therapy, it is imperative that we better understand and address medication use behaviors in patients with hypercholesterolemia.

Multiple factors have been associated with and observed to impact regular medication taking in patients being treated with agents indicated for hypercholesterolemia (Table 2). Across multiple studies, female patients and those who were currently smoking reported lower levels of or odds for being adherent to prescribed lipid-lowering agents; however, characteristics, such as patient's age, have been related to inconsistent results. ${ }^{31,35,41-43}$ Other factors shown to be predictive of poorer adherence include perceived side effects and recent initiation of treatment. ${ }^{35,43}$ Conversely, the taking of fewer medications, initiation of therapy with other cardiovascular medications, and lower copayments or levels of cost sharing have been consistently associated with better adherence or persistence. ${ }^{29-31,33,41,44}$ Additionally, a limited number of investigations have found associations between better levels of or odds for adherence and provider time during visits, perceived efficacy of therapy, and more frequent provider office visits..$^{31,32,43,44}$ However, in spite of these observations, much remains to be understood about the significant factors that influence ongoing medication use in order to best design approaches to improve medicationtaking behavior.

Table 2 Challenges to cholesterol medication adherence

\begin{tabular}{ll}
\hline Category & Barrier \\
\hline System factors & Higher cost sharing or copayments \\
& Poor patient-provider communication \\
& Lack of patient-centered medical home \\
& infrastructure \\
& Acute illness (sickness care) focus \\
Condition and & Hospital (rescue care) focus \\
treatment factors & Perceived efficacy \\
& Newly initiated patients \\
& Number of medications \\
Patient-level factors & Perceived side effects \\
& Timing of medication initiation \\
& Sex \\
\hline
\end{tabular}




\section{Intervention strategies}

A variety of approaches have been used in efforts to improve adherence to hypercholesterolemia medications. A number of these efforts have been tied not only to changes in adherence, but also to improvements in LDL cholesterol and clinical outcomes. ${ }^{45}$ Recent studies have focused on assessing strategies including: pharmacist counseling; patient reminders; education using mailed materials or direct calling; and systems-based strategies such as the lowering of copayments. However, mostly varied results have been observed across studies in terms of altering medication use, and no single approach has led to consistently positive results.

\section{Pharmacist interventions}

Pharmacist participation in encouraging adherence has been central in multiple studies. Specific involvement in interventions has leveraged numerous techniques, including phone calls, counseling, medication review, home visits, and comprehensive pharmacy care. Content for these efforts has focused on education, the importance of adherence, and prevention; thus far, information exchange has been either direct or delivered by mailed material, video, or over the phone. ${ }^{46-51}$ Outcomes related to pharmacist involvement have been mixed, with short-term and long-term changes in medication use varying between investigations, with particular methods showing promise and certain populations realizing improvements. Across studies, the combined use of pharmacist counseling or follow-up with a focus on adherence led to the most notable changes in medication use, even though consistent and significant improvements were not universal. ${ }^{46-51}$ Of particular importance are the improvements realized in newly initiated patients, as well as the changes observed compared to control after 12 months of intervention. ${ }^{46-48,50}$ Such results suggest that pharmacist participation can lead to improvements in hypercholesterolemia medication use, but the most effective means to do so, as well as whether it is sensible for intervention at the onset of therapy or once treatment has begun, require further inquiry.

\section{Reminder systems}

Reminders, provided by several mediums, have also been widely applied and with similarly varied results; such encouragement was provided by pharmacists, phone calls, through the mail, and via the use of calendar reminders. Telephone reminders, particularly when given in conjunction with educational material, appear to be especially beneficial to ongoing medication use ${ }^{46,48,52,53}$ however, universal and significant improvements have not been observed..$^{54,55}$ Other forms of reinforcement, such as mailed feedback based on theoretical constructs, have also led to positive improvements, but further inquiry into how behavioral theory applies to the taking of cholesterol medications is needed.$^{56}$ Considering these results, and depending on the methods used, simple reminders provide a potentially cost-effective means by which medication adherence can be encouraged.

By and large, the evidence from published interventions targeting adherence to hypercholesterolemia medications suggests that patients may respond best to approaches involving pharmacists, as well as to interventions including more frequent contact throughout the treatment process. However, no comparative trials directly comparing the effectiveness of different provider types in promoting adherence have been done. Moreover, a combination of approaches - rather than relying on one specific method - may be best. Beyond these approaches, the simplifying of patient dosing regimens has also shown benefit; ${ }^{57}$ however, the number of doses required to be taken per day to remain adherent to hypercholesterolemia medications has become less of an issue in recent years due to the broad availability of once-daily treatments.

\section{Systems-based strategies}

Systems-based strategies may have the most potential for effect. Promising systems-based strategies with high potential to improve cholesterol medication adherence include approaches to reduce cost sharing or to subsidize payments for essential medications, improve patient-provider communication, enhance patient-centered medical home (PCMH) infrastructure, and emphasize population-based preventive care instead of acute illness and hospital "rescue" care. However, for the most part, comparative effectiveness studies are lacking that directly compare promising alternative approaches.

Several studies have shown that even very small copayments may act as highly powerful disincentives to medication adherence for people with a low income. Tamblyn et $a^{58}$ recently demonstrated that elimination of prescription copayments for low-income groups was among the strongest factors promoting adherence. Similarly, Eaddy et $\mathrm{al}^{59}$ summarized additional strong evidence that even very low copays of US \$3-US \$5 per prescription may strongly deter adherence in low-income populations. Most recently, Watanabe et a ${ }^{60}$ determined that statin adherence among the Veterans Affairs population was higher among those without out-of-pocket expenses; however, adherence dropped in cases where statins required a copayment, but other medications were free, suggesting the importance of 
the relative cost of medications for those on a multipledrug regimen. Additionally, results from the MI FREEE Trial $^{61}$ suggested that eliminating copayments for statins could also improve adherence following a defined cardiac event. This approach may not be feasible for the population at large, but it is certainly possible for patients at highest risk of nonadherence, and associated adverse events such as strokes and heart attacks are linked with nonadherence to cholesterol-lowering medications. ${ }^{61}$ The effects of copayment adjustments through the use of vouchers have also been investigated, and limited results suggest that the use of certain generic medications may be influenced by these means, but long-term impacts still require further inquiry. ${ }^{62}$ Studies are needed to directly test alternative strategies to subsidizing out-of-pocket costs for patients at highest risk and for assessing the impact of such subsidies on major clinical outcomes and overall health care costs.

In addition to copayment adjustment, financial incentives, such as pay-for-performance, have either been introduced or suggested as a means to encourage proper medication prescribing by physicians and subsequent filling and taking by patients. While prevalent among discussions in the literature, the impact of these mechanisms is fairly scant among published research that included medication measures; however, some results have indicated the positive impact that pay-for-performance can have when targeting physicians and incorporating medication-specific measures. ${ }^{63}$ Moving forward, due to the use of statin adherence in the calculation of Medicare Part D Star Ratings, increased insight into the impact of pay-for-performance is likely, as broader attention is paid to medication adherence.

\section{Future methods}

While some progress has been realized with the methods employed to date, much room remains to improve the taking of hypercholesterolemia medications. While certain approaches appear to provide some benefit, the challenge that remains is one focused on creating the right combination of methods to target reasons for nonadherence at an individual level - reasons that are likely to vary among patients. Therefore, the means to identify and tailor to individual needs will be equally imperative in creating focused interventions. Moreover, input and effort from multiple entities is needed to improve the odds of successful behavior change (Figure 1).

\section{Practitioner role}

Avoidance of potential issues related to nonadherence in hypercholesterolemia begins with the efforts made by the prescribing physician immediately following diagnosis and the creation of an initial treatment plan. Primarily, a careful assessment of each patient's risk for cardiovascular disease will lead to more precise patient selection so that those with the most immediate need for medicinal therapy are selected for treatment. Such selection will allow the provider to naturally discuss the patient's immediate risk for detrimental outcomes and the role that cholesterol-lowering medications will play in the avoidance of these events. In these cases, it is imperative that physicians address both the medical benefits and direct costs associated with treatment so that patients have a complete set of data on which to base their treatment decision; concurrently, providers will need to be sensitive to the value placed on treatment

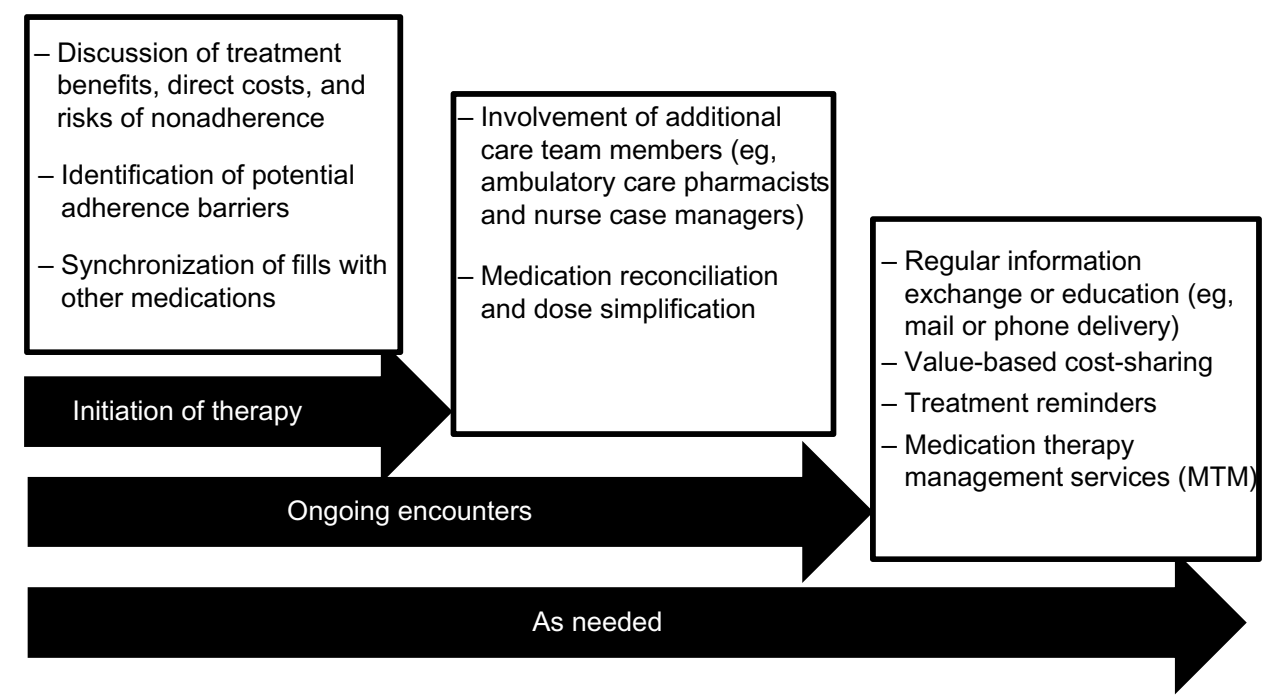

Figure I Adherence-encouraging opportunities during the treatment process. 
by each patient and consider this factor when constructing an appropriate plan.

During encounters, physicians must also be cognizant of the potential for nonadherence based on the patient's response and success with previously suggested treatments, such as nonmedication options (for example, lifestyle modification) to address high cholesterol. Furthermore, the treatment discussion must also consider challenges experienced with medication taking in other conditions, if applicable. This will also open the door to an extended conversation about the potential barriers that individual patients may have, or anticipate having, with a proposed regimen, specifically the costs of treatment both immediately and over time. Considering the chronic nature of the condition that cholesterol-lowering medications treat, the cost of addressing disease and avoiding negative outcomes by remaining adherent may be substantial; the acknowledgment of and assistance in combating costrelated issues upfront may result in the increased likelihood of patient adherence. Beyond costs, patient-specific factors, such as perceptions about their condition, perceived efficacy of treatment, and other elements outlined above that have been linked with nonadherence, must also be acknowledged to avoid future disruptions in therapy. Recognition of these factors will aid the provider in establishing a plan that may better suit the patient's needs and allow for the opportunity to have a frank discussion about the importance of remaining adherent to the agreed-upon treatment plan.

Once therapy is initiated, the monitoring of patient progress may be beneficial to the treatment process. Physicians should consider the use of electronic health record systems and the provision of pharmacy claims to observe refill behavior in patients over time. In this manner, alerts may be provided and then used to communicate with patients whose adherence may be wavering - either office staff or the provider may determine if medical attention is necessary, such as changes in therapy or if there is need for interventions to improve use - in order to uncover potential issues that may have gone unaddressed or those that have developed between encounters. Such a real-time approach may not only lead to improved medication taking, but also limit the patient's risk for an event that would have otherwise been unknown.

\section{Emerging opportunities}

Moving forward, opportunities to address medication nonadherence may build off of previous findings, such as those outlined above, but new approaches are likely to also employ emerging technologies and improved communication channels. In recent years, an increasing number of studies have examined the potential applications of mobile phones throughout the treatment process with positive results observed in several conditions. ${ }^{64-66}$ Considering the nearly ubiquitous nature of these devices, as well as the varied functions provided by advanced platforms, multiple opportunities exist to introduce mobile communication into individual regimens. Options to leverage mobile devices include automated reminders, personalized education and information, clinical data exchange, and disease tracking. By engaging patients further in their condition and treatment in this manner, it may be possible to improve how closely they follow prescribed regimens.

Research, as reviewed herein, has shown that pharmacists may have a profound impact on the taking of medications in persons with hypercholesterolemia. Considering this, care teams may benefit from including ambulatory care pharmacists in the treatment process, offering an additional layer of medicinal guidance, the provision of medication therapy management (MTM) services, and the potential for increased contact throughout the patient's treatment ${ }^{67}$ Other providers, such as nurse case managers, could also be tapped to assist in this process, having shown positive impacts in patients with dyslipidemia. ${ }^{68,69}$ Including both types of these practitioners in the patient care plans would provide more opportunities to interact with and encourage particular behaviors among patients, as well as promote the sharing of responsibility across providers, potentially leading to more efficient processes of care.

Furthermore, evidence suggests that other institutional and health policy factors may exert strong influences on adherence. Health care system overemphasis of acute illness or "sickness" care and hospital or "rescue" care results from disproportionately high reimbursements for procedures and tertiary care, while population-based primary and preventive care is underemphasized. ${ }^{70,71}$ As a result, in many communities, it is easier to get access to expensive emergency care and dialysis services than comprehensive primary care services that are most likely to emphasize cholesterol medication adherence. ${ }^{72}$ However, thus far, little data are available directly contrasting the impact of alternative payment mechanisms or alternative approaches to organizing health care services on adherence to essential preventive medications. Similarly, a lack of health system integration encouraged by the current payment approaches has resulted in poor communication between the inpatient and outpatient sectors, and poorly coordinated care for patients with the greatest need for adherence. Further studies are needed to directly test promising new models supporting improved care 
coordination and population-based care such as PCMH and accountable care organizations.

Early evidence suggests that increased emphasis on population-based primary care through investment in improved PCMH infrastructure may hold the key to improving adherence for chronic diseases like hypercholesterolemia. ${ }^{73}$ For example, Domino et $\mathrm{al}^{74}$ showed that $\mathrm{PCMH}$ care for asthma improved adherence for maintenance medication. Furthermore, a fundamental capacity for PCMH is the use of registries for disease tracking and outreach. ${ }^{73}$ Registries that are used to track and outreach patients with hypercholesterolemia have substantial capacity to improve processes and outcomes of care, yet they are, by and large, untested for hypercholesterolemia.

In addition, $\mathrm{PCMH}$-based registries are hampered by a lack of electronic pharmacy refill data that could be easily harnessed in the PCMH setting to identify and outreach nonadherent patients. Bailey et $\mathrm{al}^{75}$ demonstrated that in the case of hypertension, electronic pharmacy refill information could be used to identify patients nonadherent to antihypertensives that are thereby at increased risk for stroke and death. Bailey et al, and others, have called for policy changes to give providers broader access to real-time pharmacy refill information that may be used to effectively identify potential predictors of nonadherence and, ultimately, improve care. ${ }^{75,76}$ Specific research is needed to determine whether providing broad access to electronic pharmacy refill information to all the key providers on the care team in real time can improve processes and outcomes of care for hypercholesterolemia.

Public reporting of standard quality metrics assessing treatment and control rates for hypercholesterolemia also has the potential to improve hypercholesterolemia care. Simple reporting of quality information has been shown to lead to solid improvements in care for multiple chronic conditions. There is every reason to expect that hypercholesterolemia care would undergo similar improvements just through improved transparency at the primary care level. Further studies are needed to test these and other PCMH approaches to improving adherence to recommended care for hypercholesterolemia and other chronic conditions.

\section{Conclusion}

Nonadherence to hypercholesterolemia medications remains a prevalent public health issue. Particular approaches have been successful in improving medication-taking behaviors, but opportunities to improve adherence remain considering the varied reasons for suboptimal use. A combination of approaches that leverages effective physician communication with pharmacist involvement, ongoing patient interaction and, potentially value-based cost sharing, may lead to improved medication use and better health outcomes. Systems-based strategies to promoting adherence with cholesterol-lowering medications may possibly be the most promising over the long term, but reliable assessments of these approaches are lacking. Further studies are urgently needed to directly test promising systems-based strategies to improve adherence to potentially life-saving cholesterol medication for those at highest risk of both nonadherence and cardiovascular events.

\section{Disclosure}

The authors report no conflicts of interest in this work.

\section{References}

1. National Center for Health Statistics. Health, United States, 2012: With Special Feature on Emergency Care. Hyattsville, MD: U.S. Department of Health and Human Services; 2013. Available from: http://www.cdc. gov/nchs/data/hus/hus12.pdf\#065. Accessed May 22, 2014.

2. Rosamond W, Flegal K, Friday G, et al; American Heart Association Statistics Committee and Stroke Statistics Subcommittee. Heart disease and stroke statistics - 2007 update: a report from the American Heart Association Statistics Committee and Stroke Statistics Subcommittee. Circulation. 2007;115(5):e69-e171.

3. Fryar CD, Chen TC, Li X. Prevalence of Uncontrolled Risk Factors for Cardiovascular Disease: United States, 1999-2010. NCHS Data Brief, Number 103. Hyattsville, MD: National Center for Health Statistics; 2012.

4. Osterberg L, Blaschke T. Adherence to medication. $N$ Engl J Med. 2005;353(5):487-497.

5. IMS Institute for Healthcare Informatics. Avoidable Costs in US Healthcare: The \$200 Billion Opportunity from Using Medicines More Responsibly. Parsippany, NJ: IMS Institute for Healthcare Informatics; 2013.

6. Sokol MC, McGuigan KA, Verbrugge RR, Epstein RS. Impact of medication adherence on hospitalization risk and healthcare cost. Med Care. 2005;43(6):521-530.

7. National Center for Health Statistics. Health, United States, 2010: With Special Feature on Death and Dying. Hyattsville, MD: US Department of Health and Human Services; 2011.

8. Go AS, Mozaffarian D, Roger VL, et al; American Heart Association Statistics Committee and Stroke Statistics Subcommittee. Executive summary: heart disease and stroke statistics - 2013 update: a report from the American Heart Association. Circulation. 2013;127(1):143-152.

9. Centers for Disease Control and Prevention (CDC). Vital signs: prevalence, treatment, and control of high levels of low-density lipoprotein cholesterol - United States, 1999-2002 and 2005-200. MMWR Morb Mortal Wkly Rep. 2011;60(4):109-114.

10. Gamboa CM, Safford MM, Levitan EB, et al. Statin underuse and low prevalence of LDL-C control among US adults at high risk of coronary heart disease. Am J Med Sci. 2014;348(2):108-114.

11. Kochanek KD, Xu J, Murphy SL, Miniño AM, Kung HC. Deaths: Final Data for 2009. National Vital Statistics Reports. Vol 60, no 3. Hyattsville, MD: National Center for Health Statistics; 2012.

12. Centers for Disease Control and Prevention. National Ambulatory Medical Care Survey: 2009 Summary Tables. Atlanta, GA: Centers for Disease Control and Prevention; 2009. Available from: http://www. cdc.gov/nchs/data/ahcd/namcs_summary/2009_namcs_web_tables. pdf. Accessed June 16, 2014. 
13. Kuklina EV, Carroll MD, Shaw KM, Hirsch R. Trends in High LDL Cholesterol, Cholesterol-Lowering Medication Use, and Dietary Saturated-Fat Intake: United States, 1976-2010. NCHS Data Brief, Number 117. Hyattsville, MD: National Center for Health Statistics; 2013.

14. Heidenreich PA, Trogdon JG, Khavjou OA, et al; American Heart Association Advocacy Coordinating Committee; Stroke Council; Council on Cardiovascular Radiology and Intervention; Council on Clinical Cardiology; Council on Epidemiology and Prevention; Council on Arteriosclerosis; Thrombosis and Vascular Biology; Council on Cardiopulmonary; Critical Care; Perioperative and Resuscitation; Council on Cardiovascular Nursing; Council on the Kidney in Cardiovascular Disease; Council on Cardiovascular Surgery and Anesthesia, and Interdisciplinary Council on Quality of Care and Outcomes Research. Forecasting the future of cardiovascular disease in the United States: a policy statement from the American Heart Association. Circulation. 2011;123(8):933-944.

15. Krumholz HM. The new cholesterol and blood pressure guidelines: perspective on the path forward. JAMA. 2014;311(14):1403-1405.

16. Martin SS, Blumenthal RS. Concepts and controversies: the 2013 American College of Cardiology/American Heart Association risk assessment and cholesterol treatment guidelines. Ann Intern Med. 2014;160(5):356-358.

17. Kavousi M, Leening MJ, Nanchen D, et al. Comparison of application of the ACC/AHA guidelines, Adult Treatment Panel III guidelines, and European Society of Cardiology guidelines for cardiovascular disease prevention in a European cohort. JAMA. 2014;311(14):1416-1423.

18. Pencina MJ, Navar-Boggan AM, D'Agostino RB, et al. Application of new cholesterol guidelines to a population-based sample. $N$ Engl $J$ Med. 2014;370(15):1422-1431.

19. Reiner Z, Catapano AL, De Backer G, et al; European Association for Cardiovascular Prevention and Rehabilitation; ESC Committee for Practice Guidelines (CPG) 2008-2010 and 2010-2012 Committees. ESC/EAS guidelines for the management of dyslipidaemias: the Task Force for the management of dyslipidaemias of the European Society of Cardiology (ESC) and the European Atherosclerosis Society (EAS). Eur Heart J. 2011;32(14):1769-1818.

20. Perk J, De Backer G, Gohlke H, et al; European Association for Cardiovascular Prevention and Rehabilitation (EACPR); ESC Committee for Practice Guidelines (CPG). European Guidelines on cardiovascular disease prevention in clinical practice (version 2012). The Fifth Joint Task Force of the European Society of Cardiology and Other Societies on Cardiovascular Disease Prevention in Clinical Practice (constituted by representatives of nine societies and by invited experts). Eur Heart $J$. 2012;33(13):1635-1701.

21. Taylor F, Huffman MD, Macedo AF, et al. Statins for the primary prevention of cardiovascular disease. Cochrane Database Syst Rev. 2013;1:CD004816.

22. Muntner P, Colantonio LD, Cushman M, et al. Validation of the atherosclerotic cardiovascular disease Pooled Cohort risk equations. JAMA. 2014;311(14):1406-1415.

23. ALLHAT Officers and Coordinators for the ALLHAT Collaborative Research Group. The Antihypertensive and Lipid-Lowering Treatment to Prevent Heart Attack Trial. Major outcomes in moderately hypercholesterolemic, hypertensive patients randomized to pravastatin vs usual care: The Antihypertensive and Lipid-Lowering Treatment to Prevent Heart Attack Trial (ALLHAT-LLT). JAMA. 2002;288(23): 2998-3007.

24. Do statins have a role in primary prevention? An update. Therapeutics Letter. 2010;77:Letter 48.

25. Mihaylova B, Emberson J, Blackwell L, et al; Cholesterol Treatment Trialists' (CTT) Collaborators. The effects of lowering LDL cholesterol with statin therapy in people at low risk of vascular disease: meta-analysis of individual data from 27 randomised trials. Lancet 2012;380(9841):581-590.

26. Katz DH, Intwala SS, Stone NJ. Addressing statin adverse effects in the clinic: The 5 Ms. J Cardiovasc Pharmacol Ther. Epub April 25, 2014.
27. Cramer JA, Benedict A, Muszbek N, Keskinaslan A, Khan ZM. The significance of compliance and persistence in the treatment of diabetes, hypertension and dyslipidaemia: a review. Int J Clin Pract. 2008;62(1):76-87.

28. Huser MA, Evans TS, Berger V. Medication adherence trends with statins. Adv Ther. 2005;22(2):163-171.

29. Gibson TB, Fendrick AM, Gatwood J, Chernew ME. Gaps in treatment, treatment resumption, and cost sharing. Am J Pharm Benefits. 2012;4:e159-e165.

30. Chapman RH, Benner JS, Petrilla AA, et al. Predictors of adherence with antihypertensive and lipid-lowering therapy. Arch Intern Med. 2005;165(10):1147-1152.

31. Schultz JS, O'Donnell JC, McDonough KL, Sasane R, Meyer J. Determinants of compliance with statin therapy and low-density lipoprotein cholesterol goal attainment in a managed care population. Am J Manag Care. 2005;11(5):306-312.

32. Brookhart MA, Patrick AR, Schneeweiss S, et al. Physician follow-up and provider continuity are associated with long-term medication adherence: a study of the dynamics of statin use. Arch Intern Med. 2007;167(8):847-852.

33. Jackevicius CA, Li P, Tu JV. Prevalence, predictors, and outcomes of primary nonadherence after acute myocardial infarction. Circulation. 2008;117(8):1028-1036.

34. Ho PM, Spertus JA, Masoudi FA, et al. Impact of medication therapy discontinuation on mortality after myocardial infarction. Arch Intern Med. 2006;166(17):1842-1847.

35. Kopjar B, Sales AE, Piñeros SL, Sun H, Li YF, Hedeen AN. Adherence with statin therapy in secondary prevention of coronary heart disease in veterans administration male population. Am J Cardiol. 2003;92(9): $1106-1108$

36. DiMatteo MR, Giordani PJ, Lepper HS, Croghan TW. Patient adherence and medical treatment outcomes: a meta-analysis. Med Care. 2002;40(9):794-811.

37. Rasmussen JN, Chong A, Alter DA. Relationship between adherence to evidence-based pharmacotherapy and long-term mortality after acute myocardial infarction. JAMA. 2007;297(2):177-186.

38. Ho PM, Magid DJ, Shetterly SM, et al. Medication nonadherence is associated with a broad range of adverse outcomes in patients with coronary artery disease. Am Heart J. 2008;155(4):772-779.

39. Wei L, Wang J, Thompson P, Wong S, Struthers AD, MacDonald TM. Adherence to statin treatment and readmission of patients after myocardial infarction: a six year follow up study. Heart. 2002;88(3): 229-233.

40. Pittman DG, Chen W, Bowlin SJ, Foody JM. Adherence to statins, subsequent healthcare costs, and cardiovascular hospitalizations. Am J Cardiol. 2011;107(11):1662-1666.

41. Chan DC, Shrank WH, Cutler D, et al. Patient, physician, and payment predictors of statin adherence. Med Care. 2010;48(3):196-202.

42. Newby LK, LaPointe NM, Chen AY, et al. Long-term adherence to evidence-based secondary prevention therapies in coronary artery disease. Circulation. 2006;113(2):203-212.

43. Kiortsis DN, Giral P, Bruckert E, Turpin G. Factors associated with low compliance with lipid-lowering drugs in hyperlipidemic patients. J Clin Pharm Ther. 2000;25(6):445-451.

44. Chapman RH, Petrilla AA, Benner JS, Schwartz JS, Tang SS. Predictors of adherence to concomitant antihypertensive and lipid-lowering medications in older adults: a retrospective, cohort study. Drugs Aging. 2008;25(10):885-892.

45. Ho PM, Rumsfeld JS, Masoudi FA, et al. Effect of medication nonadherence on hospitalization and mortality among patients with diabetes mellitus. Arch Intern Med. 2006;166(17):1836-1841.

46. Faulkner MA, Wadibia EC, Lucas BD, Hilleman DE. Impact of pharmacy counseling on compliance and effectiveness of combination lipid-lowering therapy in patients undergoing coronary artery revascularization: a randomized, controlled trial. Pharmacotherapy. 2000;20(4):410-416.

47. Poston J, Loh E, Dunham W. The medication use study. Can Pharm J. 1998;131(10):31-38. 
48. Vrijens B, Belmans A, Matthys K, de Klerk E, Lesaffre E. Effect of intervention through a pharmaceutical care program on patient adherence with prescribed once-daily atorvastatin. Pharmacoepidemiol Drug Saf. 2006;15(2):115-121.

49. Lee JK, Grace KA, Taylor AJ. Effect of a pharmacy care program on medication adherence and persistence, blood pressure, and lowdensity lipoprotein cholesterol: a randomized controlled trial. JAMA. 2006;296(21):2563-2571.

50. Taitel M, Jiang J, Rudkin K, Ewing S, Duncan I. The impact of pharmacist face-to-face counseling to improve medication adherence among patients initiating statin therapy. Patient Prefer Adherence. 2012;6:323-329.

51. Peterson GM, Fitzmaurice KD, Naunton M, Vial JH, Stewart K, Krum H. Impact of pharmacist-conducted home visits on the outcomes of lipidlowering drug therapy. J Clin Pharm Ther. 2004;29(1):23-30.

52. Márquez Contreras E, Casado Martínez JJ, Corchado Albalat Y, et al. [Efficacy of an intervention to improve treatment compliance in hyperlipidemias]. Aten Primaria. 2004;33(8):443-450. Spanish.

53. Márquez Contreras E, Casado Martínez JJ, Motero Carrasco J, et al. [Therapy compliance in cases of hyperlipaemia, as measured through electronic monitors. Is a reminder calendar to avoid forgetfulness effective?]. Aten Primaria. 2007;39(12):661-668. Spanish.

54. Guthrie RM. The effects of postal and telephone reminders on compliance with pravastatin therapy in a national registry: results of the first myocardial infarction risk reduction program. Clin Ther. 2001;23(6):970-980.

55. Schectman G, Hiatt J, Hartz A. Telephone contacts do not improve adherence to niacin or bile acid sequestrant therapy. Ann Pharmacother. 1994;28(1):29-35.

56. Johnson SS, Driskell MM, Johnson JL, et al. Transtheoretical model intervention for adherence to lipid-lowering drugs. Dis Manag. 2006;9(2):102-114.

57. Brown BG, Bardsley J, Poulin D, et al. Moderate dose, three-drug therapy with niacin, lovastatin, and colestipol to reduce low-density lipoprotein cholesterol $<100 \mathrm{mg} / \mathrm{dL}$ in patients with hyperlipidemia and coronary artery disease. Am J Cardiol. 1997;80(2):111-115.

58. Tamblyn R, Eguale T, Huang A, Winslade N, Doran P. The incidence and determinants of primary nonadherence with prescribed medication in primary care: a cohort study. Ann Intern Med. 2014;160(7):441-450.

59. Eaddy MT, Cook CL, O’Day K, Burch SP, Cantrell CR. How patient cost-sharing trends affect adherence and outcomes: a literature review. P T. 2012;37(1):45-55.

60. Watanabe JH, Kazerooni R, Bounthavong M. Association of copayment with likelihood and level of adherence in new users of statins: a retrospective cohort study. J Manag Care Pharm. 2014;20(1):43-50.

61. Choudhry NK, Avorn J, Glynn RJ, et al; Post-Myocardial Infarction Free Rx Event and Economic Evaluation (MI FREEE) Trial. Full coverage for preventive medications after myocardial infarction. $N$ Engl J Med. 2011;365(22):2088-2097.

62. Bhargava V, Greg ME, Shields MC. Addition of generic medication vouchers to a pharmacist academic detailing program: effects on the generic dispensing ratio in a physician-hospital organization. J Manag Care Pharm. 2010;16(6):384-392.

63. Gilmore AS, Zhao Y, Kang N, et al. Patient outcomes and evidencebased medicine in a preferred provider organization setting: a six-year evaluation of a physician pay-for-performance program. Health Serv Res. 2007;42(6 Pt 1):2140-2159; discussion 2294-2323.

64. Fjeldsoe BS, Marshall AL, Miller YD. Behavior change interventions delivered by mobile telephone short-message service. Am J Prev Med. 2009;36(2):165-173.

65. Krishna S, Boren SA, Balas EA. Healthcare via cell phones: a systematic review. Telemed J E Health. 2009;15(3):231-240.

66. Wei J, Hollin I, Kachnowski S. A review of the use of mobile phone text messaging in clinical and healthy behaviour interventions. J Telemed Telecare. 2011;17(1):41-48.
67. Ellis SL, Carter BL, Malone DC, et al. Clinical and economic impact of ambulatory care clinical pharmacists in management of dyslipidemia in older adults: the IMPROVE study. Impact of Managed Pharmaceutical Care on Resource Utilization and Outcomes in Veterans Affairs Medical Centers. Pharmacotherapy. 2000;20(12): $1508-1516$

68. Becker DM, Allen JK. Improving compliance in your dyslipidemic patient: an evidence-based approach. $J$ Am Acad Nurse Pract. 2001;13(5):200-207.

69. Allen JK, Blumenthal RS, Margolis S, Young DR, Miller ER, Kelly K. Nurse case management of hypercholesterolemia in patients with coronary heart disease: results of a randomized clinical trial. Am Heart $J$. 2002;144(4):678-686.

70. Cosgrove DM, Fisher M, Gabow P, et al. Ten strategies to lower costs, improve quality, and engage patients: the view from leading health system CEOs. Health Aff (Millwood). 2013;32(2):321-327.

71. Bodenheimer T, Wagner EH, Grumbach K. Improving primary care for patients with chronic illness: the chronic care model, Part 2. JAMA. 2002;288(15):1909-1914.

72. Ward MM. Access to care and the incidence of end-stage renal disease due to diabetes. Diabetes Care. 2009;32(6):1032-1036.

73. Jackson GL, Powers BJ, Chatterjee R, et al. Improving patient care. The patient centered medical home. A Systematic Review. Ann Intern Med. 2013;158(3):169-178.

74. Domino ME, Humble C, Lawrence WW, Wegner S. Enhancing the medical homes model for children with asthma. Med Care. 2009;47(11):1113-1120.

75. Bailey JE, Wan JY, Tang J, Ghani MA, Cushman WC. Antihypertensive medication adherence, ambulatory visits, and risk of stroke and death. J Gen Intern Med. 2010;25(6):495-503.

76. Ferrajolo C, Arcoraci V, Sullo MG, et al. Pattern of statin use in southern italian primary care: can prescription databases be used for monitoring long-term adherence to the treatment? PLoS One. 2014;9(7):e102146.

77. Expert Panel on Detection, Evaluation, and Treatment of High Blood Cholesterol in Adults. Executive Summary of The Third Report of The National Cholesterol Education Program (NCEP) Expert Panel on Detection, Evaluation, And Treatment of High Blood Cholesterol In Adults (Adult Treatment Panel III). JAMA. 2001;285(19):2486-2497.

78. Grundy SM, Cleeman JI, Merz CN, et al; National Heart, Lung, and Blood Institute; American College of Cardiology Foundation; American Heart Association. Implications of recent clinical trials for the National Cholesterol Education Program Adult Treatment Panel III guidelines. Circulation. 2004;110(2):227-239.

79. Goff DC, Lloyd-Jones DM, Bennett G, et al. 2013 ACC/AHA guideline on the assessment of cardiovascular risk: a report of the American College of Cardiology/American Heart Association Task Force on Practice Guidelines. Circulation. 2014;129(25 Suppl 2):S49-S73.

80. Stone NJ, Robinson JG, Lichtenstein AH, et al; American College of Cardiology/American Heart Association Task Force on Practice Guidelines. 2013 ACC/AHA guideline on the treatment of blood cholesterol to reduce atherosclerotic cardiovascular risk in adults: a report of the American College of Cardiology/American Heart Association Task Force on Practice Guidelines. J Am Coll Cardiol. 2014;63(25 Pt B): 2889-2934.

81. Risk assessment tool for estimating your 10-year risk of having a heart attack [webpage on the Internet]. Bethesda, MD: National Heart, Lung, and Blood Institute; 2013. Available from: http://cvdrisk.nhlbi.nih.gov. Accessed October 14, 2014

82. Pooled cohort risk assessment equations [webpage on the Internet]. Chicago: ClinCalc LLC; 2014. Available from: http://clincalc.com/ Cardiology/ASCVD/PooledCohort.aspx. Accessed October 14, 2014. 


\section{Publish your work in this journal}

Vascular Health and Risk Management is an international, peerreviewed journal of therapeutics and risk management, focusing on concise rapid reporting of clinical studies on the processes involved in the maintenance of vascular health; the monitoring, prevention and treatment of vascular disease and its sequelae; and the involvement of metabolic disorders, particularly diabetes. This journal is indexed on PubMed Central and MedLine. The manuscript management system is completely online and includes a very quick and fair peer-review system, which is all easy to use. Visit http://www.dovepress.com/ testimonials.php to read real quotes from published authors.

Submit your manuscript here: http://www.dovepress.com/vascular-health-and-risk-management-journal 